\title{
Design de superfície: a valorização do Museu Nacional do Mar por meio da criação de artefatos
}

\author{
Irma Haensch Pereira (Currículo Lattes) \\ João Eduardo Chagas Sobral (Currículo Lattes)
}

\section{INTRODUÇÃO}

Em um território com mais de 8,5 milhões de quilômetros quadrados, o Brasil é um país de riquezas ímpares e das mais diversificadas. O seu tamanho e a sua trajetória histórica proporcionam variados contextos culturais, que se distinguem ora por sua localização geográfica, ora pela linha do tempo de seus acontecimentos.

A cidade litorânea de São Francisco do Sul, localizada ao norte de Santa Catarina, é detentora de algumas dessas riquezas que o país apresenta. Possuindo mais de 500 anos de história, a cidade é dotada de um vasto acervo cultural e histórico, como o Museu Nacional do 
Mar. Esse conteúdo histórico-cultural instigou a fazer uso do museu e de suas peculiaridades como tema de inspiração de projeto.

$O$ referencial que surge de um tema, mais precisamente local, nem sempre é explorado de modo a ultrapassar fronteiras. Muitas vezes a globalização unifica, podendo também descaracterizar os locais e suas particularidades. Paulo Freire relata em seu texto que:

\begin{abstract}
Antes de tornar-me um cidadão do mundo, fui e sou um cidadão do Recife, a que cheguei a partir de meu quintal, no bairro de Casa Amarela. Quanto mais enraizado na minha localidade, tanto mais possibilidades tenho de me espraiar, me mundializar. Ninguém se torna local a partir do universal. O caminho existencial é inverso. Eu não sou antes brasileiro para depois ser recifense. Sou primeiro recifense, pernambucano, nordestino. Depois, brasileiro, latinoamericano, gente do mundo (FREIRE, 2001, p. 25).
\end{abstract}

Ao expor embarcações, costumes e tradições náuticas brasileiras, o Museu Nacional do Mar apresenta a história cotidiana dos homens trabalhadores do mar e reforça a importância da sua significação cultural para a sociedade. Ao reconhecer a singularidade presente no museu, este se torna parte do todo, ou seja, global. Logo, como problema de pesquisa para esse projeto, surge a pergunta: como utilizar o design de superfície para contribuir com a valorização do Museu Nacional do Mar por meio da criação de artefatos que o represente?

A intenção deste projeto foi buscar referências no Museu Nacional do Mar a fim de criar artefatos a serem comercializados e admirados de maneira que não fossem restritos à região, mas também além das fronteiras. Buscou-se contribuir culturalmente para o museu e promovê-lo por meio dos subsídios que este local oferece, mais precisamente nas peculiaridades simbólicas de seu acervo, de modo a torná-las universais. Para que a valorização do museu fosse alcançada, o design de superfície foi a atividade criativa utilizada 
para reforçar a identidade do local e o design thinking, a ferramenta de inovação escolhida.

Este projeto se relacionou com a linha de pesquisa de produção do designe contexto sociocultural do mestrado profissional em Design a partir do objeto de estudo, Museu Nacional do Mar. A possibilidade de se trabalhar com o museu e com o Design de Superfície retoma estudos já realizados pelos autores anteriormente. O Museu Nacional do Mar foi o tema no trabalho de conclusão de curso da graduação e nas investigações sobre uma das áreas de Design de Superfície, a estamparia, a qual foi seu foco de estudo e área de trabalho desde sua participação na especialização da Universidade Federal de Santa Maria [UFSM], Rio Grande do Sul, em 2006.

A sociedade em constante transformação, aliada ao conteúdo histórico do museu, articulou uma oportunidade de se aprofundar no processo de investigação para inovação, unindo ao Design de Superfície o reduto cultural que o museu representa. O acervo não apenas agregou com sua riqueza de informações ao projeto sua singularidade - como também contribuiu na sua valorização e preservação diante do registro que foi realizado, tornando-se universal. Tal reapresentação de seus aspectos combinados ao Design de Superfície careceu de um ou mais suportes nos quais suas superfícies fossem elaboradas. Esses suportes foram apresentados no decorrer do desenvolvimento do projeto, uma vez que foi parte da pesquisa desvendá-los. A intenção foi que esses artefatos, independentemente do seu processo produtivo, fossem portadores da identidade cultural do Museu Nacional do Mar.

A partir do estudo das diferentes possibilidades de artefatos que representassem a intenção do projeto por meio da aplicação do Design de Superfície, foram investigados modos de produzi-los da melhor maneira possível. O estudo considerou o que o mercado já 
oferece no segmento de produtos destinados à indústria do turismo. Houve, neste projeto, a possibilidade de investigar as relações e ações do design a partir da ressignificação cultural dentro do cenário de um local como o Museu Nacional do Mar. Contemplou-se, dessa forma, a ênfase do projeto no contexto sociocultural, bem como tecnológico.

Para o desenvolvimento do projeto e a elaboração dos designs de superfície, estudou-se quatro temas: a cidade de São Francisco do Sul e o Museu Nacional do Mar; a identidade da cultura local; o design de superfície; e o design thinking. A exploração desses temas estruturou este projeto de maneira a apresentar seus assuntos e sequenciar todo o seu conteúdo.

Em um primeiro momento, o contexto do projeto foi estudado. Conhecer São Francisco do Sul e suas características históricas, culturais e geográficas tornou-se determinante, uma vez que foi o ponto de partida neste projeto para depois apresentar o Museu Nacional do Mar. Questões pertinentes à história, ao acervo, ao espaço físico e ao perfil turístico do museu auxiliaram na compreensão de suas características.

Na primeira parte da fundamentação teórica, estudou-se a identidade da cultura local e o modo como se articula. Enquanto design e território, a identidade cultural mostrou-se ponto fundamental na sua compreensão e conhecimento, tendo como base autores como Edgar e Sedgwick (2003), Geertz (1978), Engels et al. (1980) e Borges (2011). Na sequência, o design de superfície teve sua relevância ao ser observado como uma área que se utiliza de "recursos da linguagem visual como meio de expressão", segundo Rüthschilling (2013, p. 61). Ao trabalhar com diferentes materiais e superfícies, o papel, a cerâmica e os têxteis se destacam na aplicação do design de superfície, porém a possibilidade de aplicação não se restringe a eles, oportunizando que outros materiais sirvam de 
suporte aos desenhos. Por último, o design thinking se apresentou como ferramenta de inovação para o desenvolvimento do projeto. Ele atuou na estruturação do projeto em si, como também auxiliou na escolha dos artefatos a serem apresentados ao fim deste projeto.

Fundamentado em quatro temas - Museu Nacional do Mar, identidade cultural, design de superfície e design thinking-a metodologia deste projeto foi estruturada em três fases distintas. A primeira correspondeu à organização da problemática e da definição dos objetivos. A segunda fase referiu-se à realização simultânea de diferentes pesquisas - bibliográfica, imagética e de artefatos. A terceira fase foi dedicada ao projeto das superfícies aplicadas aos artefatos.

A metodologia foi baseada em Marconi e Lakatos (2003), Gil (2008) e Gerhardt e Silveira (2009). O projeto se caracterizou como uma pesquisa qualitativa de caráter exploratório que, para sua realização, se utilizou das pesquisas bibliográfica, imagética e de produtos, bem como se apresentou como uma pesquisa participante.

A junção dos diferentes tipos de pesquisa ocorreu tanto por causa do objeto de estudo que direciona o projeto, como pelos artefatos que foram escolhidos como suportes para aplicação do design de superfície. Esses diferentes modos de investigação foram unidos à pesquisa participante, uma vez que a pesquisadores fez parte do método de análise científica, envolvendo-se e identificandose, também, com o objeto de estudo.

Ao discorrer sobre identidade cultural, design de superfície e design thinking, o desenvolvimento do projeto recebeu um alicerce no qual os seus conteúdos foram expostos e deram suporte para a elaboração dos resultados que foram obtidos. Acredita-se que associar simbologias e emoções que representem o acervo cultural do Museu Nacional do Mar por meio do design de superfície foi o 
desafio no desenvolvimento de artefatos. Sendo o museu um local em que se concentram riquezas culturais, reforçar tal concentração e atrair novos olhares foi a intenção do projeto de Design de Superfície: a valorização do Museu Nacional do Mar por meio da criação de artefatos.

\section{PROJETO}

O processo de criação deste projeto se deu pela busca de referência na identidade cultural pertencente ao Museu Nacional do Mar (Figura 1). O design pode ser analisado tanto como uma atividade projetual a ser utilizada no desenvolvimento de artefatos que expressam tal identidade cultural, como também na busca por métodos que alcançam a inovação desejada. Ao se apresentar como elemento de grande valia para a inovação, o design impulsiona e gera valor que é percebido pelas pessoas, podendo atuar em produto, processo ou serviço.

Figura 1 - Embarcações do Museu Nacional do Mar

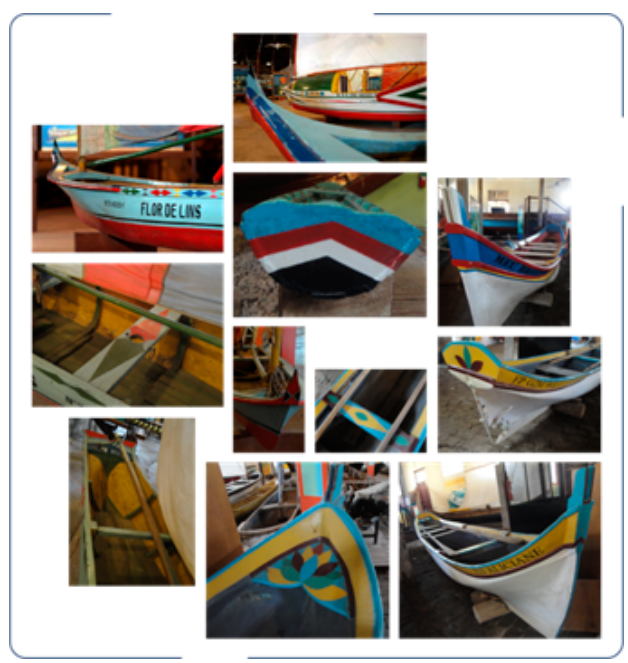

Fonte: primária e Tempo Editoral (empresa) 
A fim de agregar qualidade ao resultado do projeto, o "pensar design" foi a metodologia que tinha os princípios favoráveis ao seu desenvolvimento, pois para o sucesso de sua implantação necessitava-se alcançar os princípios do design thinking. São estes: ser tecnicamente viável de ser produzido, financeiramente possível de ser realizado e que resultasse em artefatos desejáveis pelas pessoas que frequentam o museu. Quando essas três características estão presentes, é tido como o ideal para um projeto.

Para que se obtivesse tal resultado pela aplicação do design thinking em um projeto, foi preciso observar que ele possuía etapas a serem cumpridas em seu processo. Vianna et al. (2012) apresentam as etapas como sendo a fase de imersão, de análise e síntese, de ideação e de prototipação.

Enquanto parte do projeto direcionado a elaborar artefatos para o Museu Nacional do Mar, entendeu-se que a fase de imersão, pela qual se compreende o problema levantado no projeto, foi aquela em que se aproximou do contexto do problema e que os assuntos relevantes a ele foram pesquisados. As pesquisas bibliográfica e simbólica pertenceram a essa fase. A Figura 2 mostra essa etapa sinalizada pelo fundo amarelo da imagem, que ocorreu em paralelo com a fase de análise e síntese, uma vez que o processo de avanço da pesquisa não necessitava ser linear e permitia que o benchmarketing e a pesquisa de campo fossem feitos simultaneamente. 
Figura 2 - Etapas do processo de design thinking aplicadas no projeto

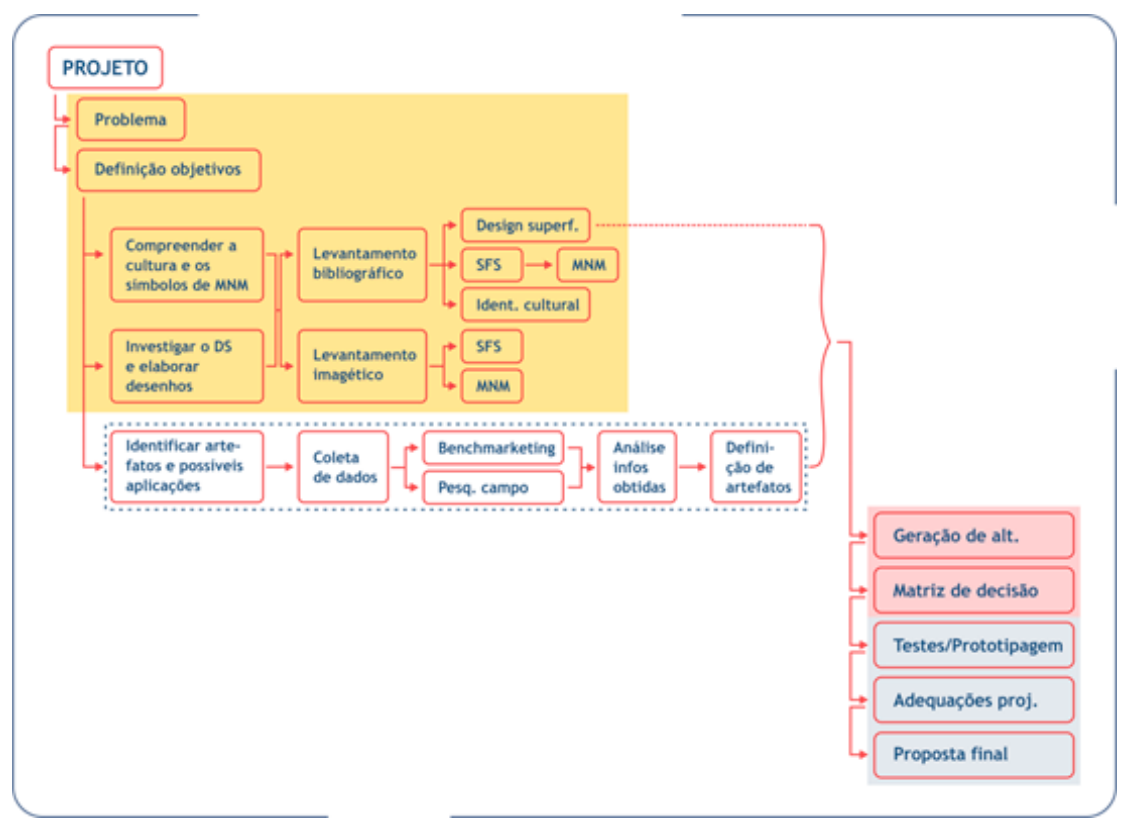

Fonte: primária (2015)

A fase de análise e síntese, também chamada de fase de interpretação, não equivaleu a uma fase isolada do processo. Contudo, ela foi uma parte do conjunto de ações desse processo e ocorreu simultaneamente a outras fases. Foi nela que as informações coletadas durante o levantamento de dados foram analisadas e organizadas de maneira a auxiliar na compreensão do problema (VIANNA et al., 2012). A área circundada pelo pontilhado azul, na Figura 2, apresenta o benchmarketing ${ }^{1}$ e a pesquisa de campo como o meio de reconhecer o que o mercado tem oferecido em situações similares às do museu. Tais situações se referem à procura de transmitir a identidade de um determinado local em artefatos que o representem e, ao serem adquiridos, são levados para outros locais.

\footnotetext{
${ }^{1}$ Análise das melhores técnicas e processos já em prática no mercado, segundo Baxter (2011, p. 187).
} 
Descobriu-se tal similaridade em projetos como Bicho do Mar de Dentro, proveniente da área da Lagoa dos Patos, no sul do Rio Grande do Sul, e também no projeto orientado pelo Laboratório Piracema de Design com os artesãos de Inhamuns, no sudoeste do Ceará. Encontrou-se, contudo, no projeto Sou Curitiba Souvenirs o exemplo ideal a ser analisado, seja pelas características presentes do projeto, seja pela possibilidade econômica de se visitar as lojas, seja pela proximidade geográfica do local, que oportunizou os autores conhecer os espaços do projeto com os produtos sendo comercializados. O projeto Sou Curitiba Souvenirs é um projeto de economia criativa e entre os seus objetivos está produzir um conjunto de produtos que tenham qualidade e atender às necessidades e aos desejos dos turistas, de modo a materializar as experiências vividas e fortalecer os laços com a cidade.

A pesquisa detalhada do benchmarketing enfatizou o uso de técnicas como a serigrafia e o corte a laser, bem como oportunizou considerar uma ampla variedade de materiais que pudessem receber tais aplicações, como o papel, a cerâmica e o tecido, por exemplo. Compreendeu-se que o processo resultante de produção não é restrito a ser industrial e/ou artesanal. Pretendeu-se apenas que os artefatos fossem portadores da identidade cultural local e que pudessem ser comercializados na loja de souvenires; do Museu Nacional do Mar, permitindo que o conjunto de símbolos locais se tornasse universal, ultrapassando a localização geográfica na qual se encontra inserido.

A fase de ideação, representada na Figura 2 como a de fundo cor-de-rosa, foi aquela em que se buscou gerar "ideias inovadoras através de atividades colaborativas que estimulem a criatividade" (VIANNA, 2012, p. 17). Para tanto, fez-se uso de ferramentas de síntese e gerou-se soluções que estivessem em conformidade com 
o contexto trabalhado no projeto. Considerou-se que os produtos escolhidos oferecessem perspectivas de vendas, ou seja, deveriam ser mensageiros do conteúdo do Museu Nacional do Mar e levar tal mensagem com quem adquirisse os artefatos, bem como os produtos deveriam ser eficientes para o seu transporte durante uma viagem, uma vez que os frequentadores do Museu são turistas. Critérios de tamanho, peso e resistência se apresentaram como sendo primordiais entre as características que os produtos deveriam ter. Somaram-se a esses critérios as características do museu e os princípios do design thinking: ser rentável para o museu, desejável para os turistas e tecnicamente possível de ser confeccionado.

A pesquisa de benchmarketing apresentou uma variedade de produtos formulados com os mais diferentes materiais e por meio das mais diversas técnicas, de maneira a responderem favoravelmente a esses critérios. Essa observação direcionou a escolha de alguns produtos a serem trabalhados. Foram eles: uma bolsa, uma caderneta de anotações e uma caneca. Esses produtos foram escolhidos por atenderem aos critérios comerciais estabelecidos; por serem produtos comumente consumidos por compradores; por serem confeccionados com técnicas bem difundidas; e por possuírem qualidades funcionais e estéticas, relacionadas com o uso e com o significado simbólico respectivamente. Também favoreceram o uso de três diferentes materiais: o tecido, o papel e a cerâmica.

Com o intuito de aplicar o design de superfície em artefatos que sejam souvenirs e torná-los atraentes, para que sejam comprados e levados para outros lugares, observou-se que para as perspectivas de aplicação dos desenhos gerados devia-se levar em consideração que as formas, os traços e as cores presentes nas peças de exposição do Museu Nacional do Mar fossem percebidas nos novos artefatos. Para tanto, uma cartela de cores foi montada a partir das cores 
presentes no museu, além de painéis contendo imagens das embarcações e detalhes de seus grafismos. Esboços foram feitos sobre essas observações e formas foram desenhadas e vetorizadas. Elas se apresentaram como elementos visuais a compor designs de superfícies pela repetição e fazendo uso de efeitos de translação ${ }^{2}$, rotação ${ }^{3}$ e reflexão ${ }^{4}$. Tal ação oportunizou a criação de 88 alternativas, como pode ser notado nos exemplos da Figura 3.

Figura 3 - Geração de alternativas

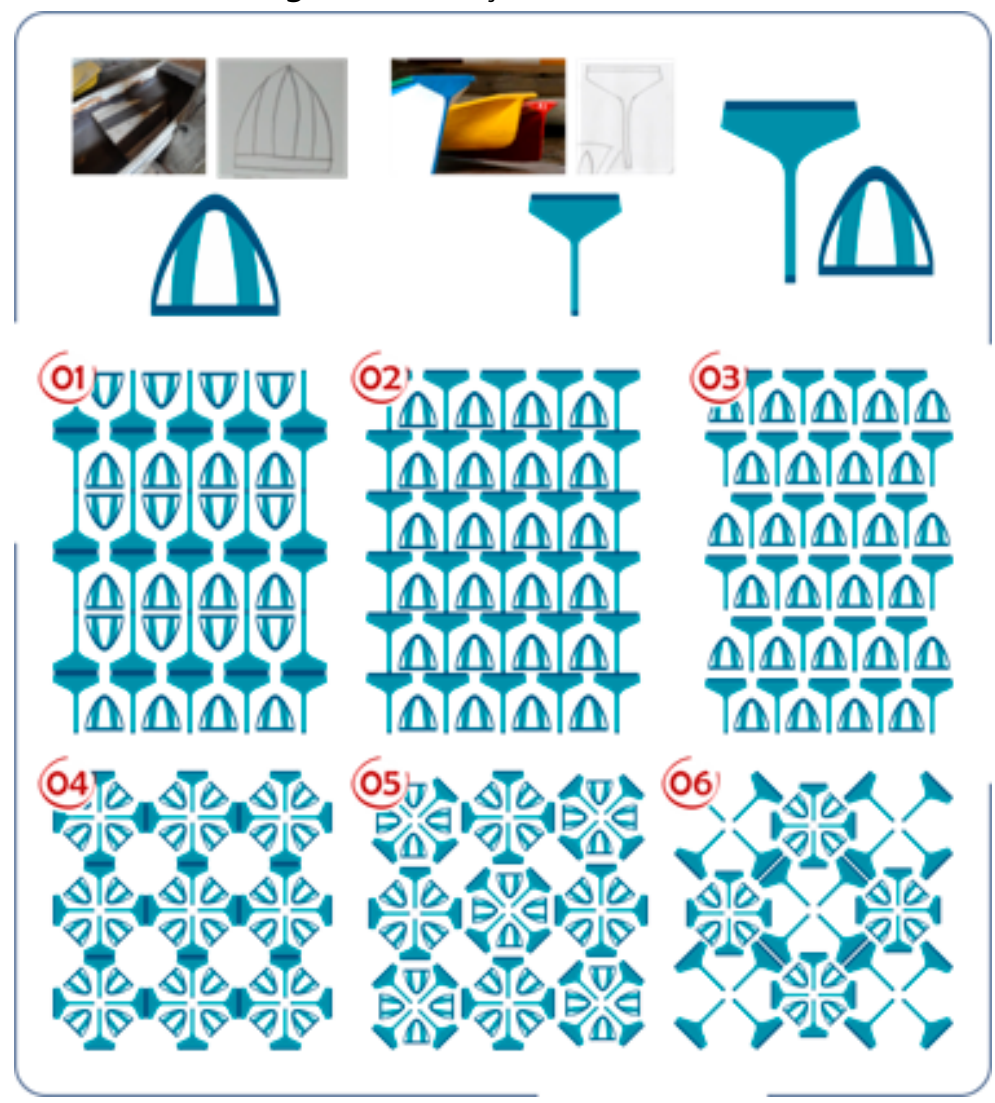

Fonte: primária (2015)

2 O módulo mantém sua direção original e desloca-se sobre um eixo (RÜTHSCHILLING, 2008, p. 68).

${ }^{3}$ Deslocamento radial do módulo ao redor de um ponto (Id. Ibid., p. 68).

${ }^{4}$ Espelhamento em relação a um eixo ou a ambos (Id. Ibid., p. 68). 
A fim de compor uma minicoleção de designs de superfície, selecionou-se dez alternativas entre as 88 geradas. Para isso, utilizou-se a matriz de decisão, baseada em Baxter (2011), como ferramenta de seleção. A partir de sua aplicação, as alternativas com maior pontuação foram selecionadas para compor os desenhos de superfície desse projeto. Elas podem ser vistas na Figura 4 e esse conjunto de alternativas selecionadas se apresenta como desenhos barrados e metragens corridas.

Figura 4 - Alternativas selecionadas

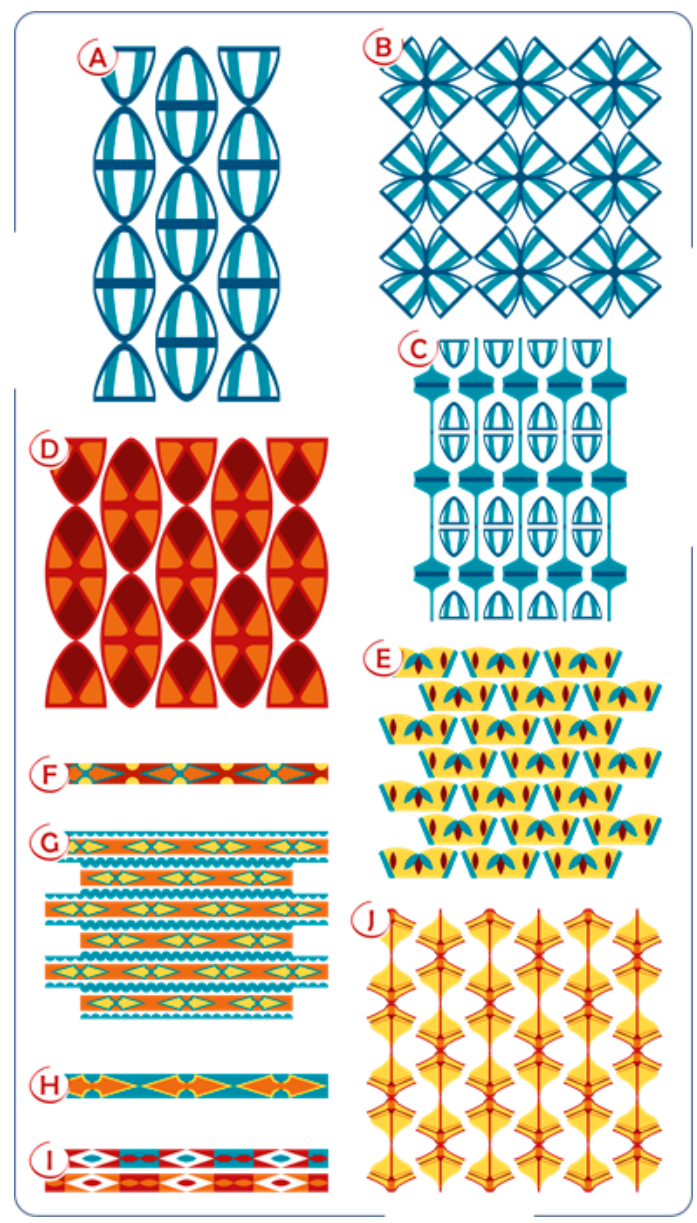

Fonte: primária (2015) 
Cores quentes como vermelho, alaranjado e amarelo contrastam com as cores frias, como os tons de azul. A cor branca soma ao grupo de cores utilizadas e sugere leveza, remetendo à simplicidade da vida ao mar. As formas enfatizam detalhes encontrados no acervo do Museu Nacional do Mar.

Ao definir-se os produtos a serem confeccionados e os designs de superfície a serem aplicados, a fase da prototipação teve início. Ela esteve relacionada com o momento em que as ideias geradas foram materializadas e experimentadas por meio de protótipos, de maneira que fossem refinadas e validadas. Os produtos selecionados durante a fase de ideação tiveram diferentes especificações, como se pode observar na Figura 5.

Figura 5 - Especificações dos produtos confeccionados

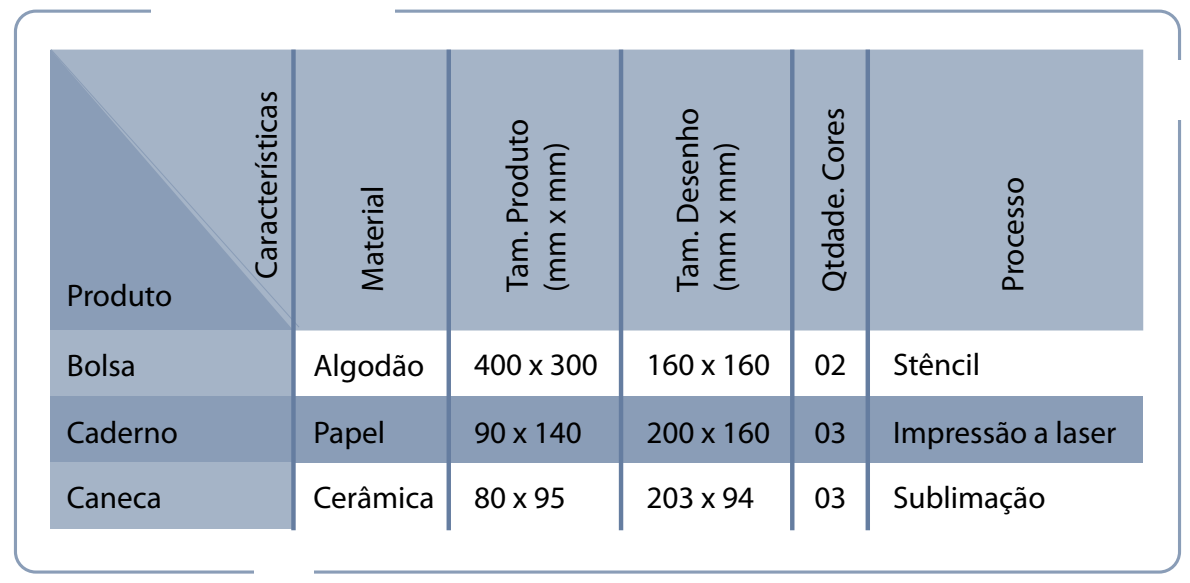

Fonte: primária (2015)

A Figura 6 apresenta os produtos confeccionados. São modelos físicos que foram prototipados para uma melhor visualização e possível adequação para futuras implantações do projeto. Este projeto pode seguir variados desdobramentos, contudo ele se encerrou com a fase de prototipação das peças e sua apresentação. 
Figura 6 - Produtos confeccionados

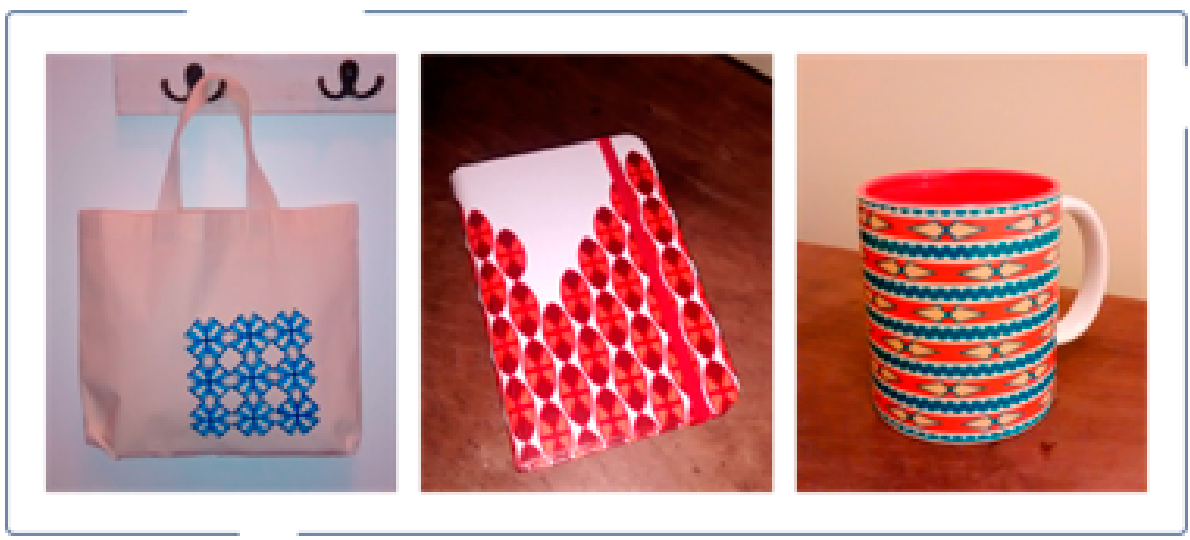

Fonte: primária (2015)

O seu objetivo principal, que era reapresentar o Museu Nacional do Mar por meio do design de superfície para criação de artefatos que valorizassem sua identidade cultural, foi alcançado.

\section{CONSIDERAÇÕES FINAIS}

O imenso tamanho e a trajetória histórica proporcionam ao Brasil variados contextos culturais. A cidade de São Francisco do Sul é um deles e detém parte desse vasto acervo cultural e histórico nacional. Além disso, é nela que está localizado o Museu Nacional do Mar, tema de inspiração deste projeto.

Muitas vezes, a atuação da globalização em unificar acaba por descaracterizar locais e faz com que peculiaridades pertencentes a espaços como o do museu não se tornem conhecidas e universais. Logo, em vista de valorizar o conteúdo exposto no museu, ressignificálo e permitir que ele se estenda além de suas fronteiras, surgiu a seguinte problemática que foi trabalhada neste projeto: como utilizar o design de superfície para contribuir com a valorização do museu por meio da criação de artefatos? 
A fim de que uma solução fosse encontrada, buscou-se referências na cidade em que o museu se encontra, bem como no próprio espaço do museu. Para que a sua valorização fosse alcançada, o design de superfície foi a atividade criativa utilizada para reforçar a identidade cultural do local; e o design thinking, a ferramenta de inovação escolhida. Evidencia-se dessa maneira que o projeto foi fundamentado em quatro temas - cidade de São Francisco do Sul e Museu Nacional do Mar; identidade cultural; design de superfície; e design thinking. A sua exploração estruturou o projeto de maneira a apresentar seus assuntos e sequenciar todo o conteúdo do projeto. As pesquisas bibliográfica, simbólica e de produtos foram utilizadas, caracterizando a pesquisa como qualitativa de caráter exploratório e também como pesquisa participante.

Como ferramenta de inovação, o design thinking permitiu que as diferentes pesquisas fossem distribuídas nas quatro etapas sugeridas pela ferramenta. Essa ação concedeu organização ao desenvolvimento do projeto e auxiliou na escolha dos artefatos elaborados e portadores dos desenhos gerados.

Os princípios do design thinking deram suporte para que os produtos finais - bolsa, caderneta de anotações e caneca - fossem concebidos a partir da observação de serem viáveis tecnicamente na sua confecção, rentáveis financeiramente e desejáveis para os visitantes do museu.

A sustentabilidade cultural e financeira do museu é alcançada quando os artefatos produzidos são: portadores da identidade da cultura local, comercializados na loja de souvenirs e adquiridos pelos turistas que acabam por promover o museu. Dessa forma, oportuniza-se a criação de uma renda alternativa para o museu e traz contribuição cultural para a sociedade, uma vez que sensibiliza o Museu Nacional do Mar para as questões simbólicas e de sua 
identidade cultural. Acredita-se que o projeto desenvolvido reforçou o vasto acervo cultural do museu e valorizou o seu conjunto de símbolos locais por meio da emoção e por possibilitar que estes ultrapassem a localização geográfica na qual estão inseridos.

A oportunidade de aprofundar no processo de investigação para inovação une o reduto cultural que o museu representa ao Design de Superfície. $O$ acervo não apenas agregou com sua riqueza de informações ao projeto - sua singularidade-como também contribuiu na sua valorização e preservação diante do registro a ser realizado, tornando-se universal. Tal reapresentação de seus aspectos combinados ao Design de Superfície fez uso de suportes nos quais suas superfícies fossem elaboradas por meio do estudo de grafismos, cores, materiais e técnicas de aplicação.

A possibilidade de se trabalhar com o museu e com o Design de Superfície retoma estudos já realizados pelos autores. O desafio de procurar mais respostas sob um novo olhar oportunizou que os detalhes presentes nas peças expostas no museu pudessem se destacar e ser fonte primordial para a criação de novos desenhos a serem aplicados em diferentes artefatos. Fazer uso da identidade cultural presente no acervo do museu, valorizá-la e ressignificá-la por meio da aplicação de suas cores, formas e traços em designs de superfície, representando a simplicidade da vida dos homens que lidam no mar, foram os critérios estabelecidos ao projeto para alcançar os resultados.

Observa-se a possibilidade em dar continuidade com a pesquisa e estendê-la a projetos futuros a fim de que seja aplicada no Museu Nacional do Mar. Pretende-se também que o material gerado seja publicado e contribua com pesquisas para a comunidade acadêmica e profissional. 


\section{REFERÊNCIAS}

BAXTER, M. Projeto de produto: guia prático para o design de novos produtos. 3. ed. São Paulo: Blucher, 2011.

BORGES, A. Design + Artesanato: o caminho brasileiro. São Paulo: Terceiro Nome, 2011.

EDGAR, A.; SEDGWICK, P. Teoria da cultural de A a Z: conceitos-chave para entender o mundo contemporâneo. São Paulo: Contexto, 2003.

ENGELS, F. et al. $\mathbf{O}$ papel da cultura nas ciências sociais. Porto Alegre: Editorial Villa Martha Ltda., 1980.

FREIRE, P. À sombra desta mangueira. São Paulo: Olho Dágua, 2001.

GEERTZ, C. A interpretação das culturas. Rio de Janeiro: Zahar, 1978.

GERHARDT, T. E.; SILVEIRA, D. T.. Métodos de pesquisa. Porto Alegre: Editora da UFRGS, 2009.

GIL, Antonio Carlos. Métodos e técnicas de pesquisa social. 6. ed. São Paulo: Atlas, 2008.

MARCONI, M. A.; LAKATOS, E. M. Fundamentos de metodologia científica. 5. ed. São Paulo: Atlas, 2003.

RÜTHSCHILLING, E. A. Design de superfície. Porto Alegre: Editora da UFRGS, 2008.

SOU CURITIBA. Souvenirs. Disponível em: <http://sites.pr.sebrae. com.br/soucuritiba/>. Acesso em: 14 set. 2014.

VIANNA, M. et al. Design Thinking: inovação em negócios. Rio de Janeiro: MJV Press, 2012. 
